\title{
ESCRITURA Y MODERNIZACIÓN: LA DOMESTICACIÓN DE LA BARBARIE
}

POR

Beatriz González Stephan

Universidad Simón Bolívar

La modernización en América Latina fue un proceso lento, complejo, lleno de contradicciones, que abarcó casi toda la centuria anterior y se extendió hasta las primeras décadas del presente siglo. Obviamente tiene una etapa - lo que se conoce como Modernismo- donde los elementos que apostaban a la modernización de las sociedades latinoamericanas alcanzaron por primera vez una más clara y notoria objetivación histórica, al menos en ciertos escenarios de la vida nacional. Las tensiones entre el campo y la fisonomía que iban adquiriendo las ciudades se perfilaron como uno de los ejes centrales que direccionaron gran parte de los discursos culturales. La modernización ejerció una progresiva fascinación sobre ciertos sectores sociales captando cada vez más adeptos, no sin fuertes resistencias por parte de una numerosa población rural y también urbana que seguía defendiendo los valores de la tradición.

La consigna era domesticar lo que se consideraba "barbarie"; tanto campos como ciudades, hombres y hábitos, ideas y sensibilidades, debían ajustarse a los moldes de una modernidad europea, abandonar viejas tradiciones, o mejor aún, sobreponer a un cuerpo social ahora tenido por "bárbaro" - según los nuevos aires del liberalismo- modos y maneras que remedaran tanto a las ciudades y naciones, hombres y costumbres europeos. No sólo quizás, sino seguramente, la modernización fue el más vertiginoso y complejo baile de máscaras de la historia cultural del continente. La persistencia de estructuras y mentalidades fuertemente ligadas a un complejo de tradiciones sedimentadas a través del largo período colonial, aunque entraron en una fase de importante crisis, sufrieron no sólo un reacomodo ante el embate de las nuevas tendencias, sino se hibridizaron aún más al incorporar a título de máscara o parapeto elementos de la modernidad. Ya en las últimas décadas del siglo, al menos en las grandes y medianas ciudades del continente, ser moderno o estar a la moda, es decir, parecer europeo o haber asimilado el estilo de vida de las metrópolis francesa o anglosajona era casi un imperativo; lo que demuestra, por otro lado, el apremio por encubrir compulsivamente un sustrato de vieja data hispánica y católica que permanecía profundamente arraigado en las sensibilidades sociales.

Aunque muchos aspectos de la vida social efectivamente se modernizaron, otros tantos permanecieron en la superficie, como mera utilería del gran teatro que se abría con el crecimiento de las ciudades; y con ello, la introducción de una variedad, hasta entonces desconocida, de entretenimientos sociales que sacaban a la población urbana de sus casas 
a las calles, a las plazas, a los teatros, a los cafés, a los hipódromos, a las salas de baile, a restaurantes, a pasear en sus carruajes último modelo por las amplias avenidas recientemente inauguradas. Estos nuevos quehaceres demandaban también una variada toilette acorde con estos variados escenarios.

Entre la vasta agenda que implicaba el proyecto de construcción de las nuevas naciones, uno de los aspectos no menos decisivos era la modelación de los hombres y mujeres capaces de funcionar en concordancia con el nuevo estilo urbano de vida que se estaba deseando como emblema de la soñada "civilización". Es decir, el proyecto nacional implicaba la elaboración de un nuevo entramado cultural, de una nueva red simbólica que direccionara -al menos en los grupos sociales ilustrados y urbanos- el horizonte de un imaginario de esa comunidad nacional; el mapeado no menos ilusorio de un territorio cuyas fronteras sólo se delimitaban sobre papeles; el diseño de símbolos emblemáticos que en una operación metonímica se pudiese reconocer en ellos la patria, desde luego más abstracta que concreta; la escrituración de una historiografía que lograra el adecuado efecto de un pasado heroico y glorioso lleno de silenciamientos significativos y figuras hipertrofiadas convenientes a la magnificación del nuevo Estado nacional; pero, sobre todo, la modelación de un tipo de ciudadano que debía habitar las ciudades de esas repúblicas.

A diferencia del proceso europeo, la formación de los estados-naciones en América Latina adoptó vías más artificiales, es decir, casi impuestas por decreto, o desde "arriba". En este sentido, si bien la construcción de cualquier nación es siempre una operación artificial, cultural o ideológica - según los planteamientos de Benedict Anderson y Homi Bhabha- en el caso de los países latinoamericanos, donde el peso de las economías y culturas locales operó con una gran fuerza centrífuga contraria al proyecto de "unidad" nacional deseado por los grupos sociales capitalinos, los factores "artificiales" debieron tener probablemente una incidencia más definitoria para lograr un efecto relativamente convincente, al menos dentro del imaginario de cierta colectividad, de estar viviendo dentro de una nación, dentro de un territorio con fronteras bien demarcadas, la sensación de reconocerse en una historia y pasados comunes; en definitiva: la confianza depositada en la capacidad evocadora que tenía la escritura y la prensa como medio para in-formar al imaginario de los lectores de esas nuevas realidades. Había que crear la nación; pero, en especial, forjar los actores y escenarios que sirvieran de base para la existencia de esa nación, que, al fin y al cabo, se concentraba en los centros urbanos donde se vivía de acuerdo a los códigos de la "civilización". Sabemos que la prensa y la folletería, así como las novelas por entrega, jugaron un rol entrañable en la construcción de ese nuevo imaginario, de nuevas sensibilidades, y la canalización de múltiples contradicciones que sin duda generaba esa ficticia unidad nacional como la ilusoria sociedad democrática postindependista.

Dentro del proyecto nacional ocupó un espacio importante y no menos decisivo la proliferación de un género menor de prácticas discursivas orientadas a atender el comportamiento que debían asumir los habitantes de la ciudad: se trata de los "manuales de urbanidad", o con otros encabezados, las "lecciones de buena crianza de moral de mundo", los "catecismos de urbanidad civil y cristiana", los "manuales de buenas maneras". Entre la profusión de esta clase de textos, el que ha gozado de mayor difusión, no sólo en la Venezuela del siglo XIX sino en todo el mundo hispanohablante, ha sido y aún sigue 
siendo el Manual de urbanidad y buenas maneras (1854) del venezolano Manuel Antonio Carreño. Sus ediciones, reediciones y adaptaciones son ya incontables. Durante el gobierno de Guzmán Blanco (1870-1888), período por lo demás de la consolidación del Estado nacional y acelerada materialización de las nuevas condiciones urbanas y burguesas de vida, el Manual de Carreño alcanzó a tener entre 1874 y 1877 cuatro ediciones que se agotaron rápidamente. Era evidente que ya existía un numeroso público ávido de ajustar sus maneras a las que prescribía éste u otros manuales al uso para insertarse rápida y exitosamente en la dinámica que exigía la vida urbana. La cuestión era ser un hombre o mujer de apariencia "civilizada"; que sus modales no dejaran traslucir ningún rasgo o gesto que recordara viejos usos rurales, probablemente tildados de "inciviles" o "bárbaros" por esta nueva sociedad cada vez más estirada como moderna.

La nueva arquitectura urbana, que amplió el espectro de actividades sociales, obligó, en cierto modo, a una distribución más definida de los espacios públicos y privados; en otras palabras, definir exactamente las zonas de lo público y de lo privado, así como los roles conductuales de los hombres y mujeres que transitarían por ese orden recientemente creado. Había que organizar ciudades; transformar lo que quedaba de aldea colonial en urbes con edificaciones que sirvieran al poder civil del Estado; racionalizar los espacios recreativos y mejorar los servicios públicos (la construcción de acueductos, mataderos, la canalización de aguas negras, el alumbrado eléctrico, son ejemplos de ello); y, desde luego, también construir ciudadanos, y reducir en ellos las singularidades individuales; acomodarlos a un ritmo de funcionamiento; establecer formas de ocupaciones determinadas y rutinizar los ciclos de actividad y de conducta. El manual (en tanto género discursivo específico) pretende urbanizar a sus lectores; pretende hacer menos traumático el paso de una vida a puertas cerradas a una de teatros, calles y lugares públicos. El manual será la ley del buen ciudadano.

El orden era imperativo; y este orden implicaba la construcción - ahora en el sentido de limitación y demarcación — de nuevos actores sociales, que debían, a partir de la lectura, moldear sus hábitos "bárbaros" a los nuevos límites conductuales señalados por la escritura. De este modo, la escritura del Manual funciona dentro del campo institucional que despliega la autoridad del libro — en su relación concomitante entre escritura y poder- como la regulación/reglamentación de nuevas jerarquías, la sujeción cuidadosa y controlada de las subjetividades y deseos, el etiquetamiento de los impulsos espontáneos y naturales, la negación de las funciones orgánicas, la fragmentación y encasillamiento de todos los movimientos del propio cuerpo y del cuerpo social, la mediatización artificiosa entre el hombre y las cosas, en fin: la domesticación de la sensibilidad "bárbara".

Las estrategias que abraza el proyecto de construcción nacional incluyendo las del ciudadano, guardan una implícita relación con el poder de la escritura. La escritura se erige en el espacio de la ley, de la autoridad, en el poder fundacional y creador de las nuevas entidades. Como práctica social, genera un espacio adecuado (ideal) donde el mundo informe de la "barbarie" — el mundo extraño a la escritura - entra en el orden del discurso en términos de la deseada "civilización". Brevemente, escribir es dotar a esas nuevas naciones de civilización, porque el logos que controla la escritura distribuye, decide y define -obviamente para el imaginario colectivo- qué instancias o espacios se van a corresponder con el caos, con la anti-ley, con la barbarie. En este sentido, los signos 
deciden la cualidad de las cosas; y, más aún, si éstas son cosas, qué tipo de cosas son, o simplemente si son nada. La palabra escrita informa, ordena, organiza la legibilidad y comprensión del mundo en términos maniqueos de inclusiones - si se adecúan al orden creado por el discurso- y de exclusiones - si su naturaleza se resiste a entrar en los límites de la escritura.

Escribir, al menos durante la primera mitad del siglo XIX, respondía a la necesidad de ordenar e instaurar la lógica de la civilización; pero, a la vez, era un ejercicio previo y sobredeterminante de la modernización. Era dar forma anticipada al sueño modernizador. La palabra llena los vacíos: construye estados, ciudades, fronteras, diseña geografías para ser pobladas, modela a sus habitantes. $Y$ es en este sentido que la especificidad de la escritura de estos manuales va dirigida a la construcción del nuevo sujeto social deseado como protagonista del proyecto modernizador. Si lo vemos de otro modo, no hubo manuales para ser un buen llanero, gaucho o campesino. Estas categorías humanas permanecieron fuera del orden, de la ley; en todo caso fueron lo "otro", el "bandido", lo que hubo que representar también en los términos del anti-modelo deseado.

Si en términos generales, la escritura abrió el espacio de la civitas y permitió existir dentro de sus fronteras el régimen de la legalidad, el manual adquirió, en este sentido, una modalidad escriturada que duplicó esta misma condición reguladora: es una escritura que organiza la naturaleza de su propio discurso en términos de una rigurosa e interminable tabla de reglamentos, cuya disposición obedece a una rígida secuencia numérica propia de las constituciones. Al igual que éstas, que son más bien la expresión oficial de la voz del Estado, el manual vendría a ser la expresión doméstica o familiar que regula los aspectos privados y públicos de los ciudadanos.

La formalización escrituraria del manual es esencialmente normativa; la norma es su razón de ser; es el discurso de la propia legalidad. Precede casi a los demás discursos fundacionales porque es primigenio; establece antes que cualquier otro los espacios, límites y condiciones en que deberá moverse el imaginario de la "civilización", el imaginario de la modernización. Prescribe la conducta que deberán adoptar los ciudadanos que luego circularán por esas urbes cuando se haga efectiva esa vida citadina en el último tercio del siglo.

Sus términos son impositivos y absolutos como todo discurso legal. Es la misma expresión de la ley. Dicta un orden de cosas y exige obediencia. Traza sin ambigüedades claros límites de las zonas permitidas y las prohibidas. Si de hecho, como señalamos, la escritura es norma, es fundadora de un orden, la escritura del manual duplica también el control del imaginario, ya que la autoridad indiscutible que se adjudica el sujeto del discurso vela y vigila el cuerpo, el deseo y la conciencia de sus lectores. Carreño en los "Principios Generales" de su Manual impone enfáticamente que "es una regla importante de urbanidad el someternos a los usos de etiqueta" (10, subrayado mío), y, en otra parte, que "sin la observancia de estas reglas, más o menos perfectas, segúnel grado de civilización de cada país, los hombres no podrían inspirarse ninguna especie de amor ni estimación; no habría medio de cultivar la sociabilidad, que es el principio de la conservación y progreso de los pueblos, y la existencia de toda sociedad bien ordenada" (6, subrayado mío). Las relaciones de contigüidad que supone el dominio de la escritura/lectura para poder acceder al espacio de la civilización, y que ésta supone la configuración de un orden rígidamente controlado, 
a su vez, por los límites inflexibles de la escritura, pone en evidencia los nuevos supuestos implicados en el proyecto modernizador. Una línea tajante demarca el espacio del "adentro" que construye la escritura ("el sometimiento a las reglas", "el deber de observar la más severa etiqueta") y del "afuera" (la "incivilidad", la "vulgaridad", la "grosería"), es decir, cualquier propuesta cultural que atente contra aquel orden. Podemos adelantar que los valores que subyacen en el Manual refuerzan, en otro plano, la ideología positivista que servirá de fundamento y justificación a la modalidad conservadora y autoritaria que asumirá el liberalismo en América Latina en la segunda mitad del siglo.

Para completar el circuito que supone esta escritura, como condición sine que non del ser civilizado, es imprescindible la lectura. Sólo podrá acceder a la categoría de ciudadano quien sepa leer; no sólo quien lea podrá entrar en ese orden, sino también sólo aquel que ajuste su imaginación, su cuerpo, sus deseos y su expresión a la escritura. Así, escritura y lectura como actos fundacionales de la nación y necesarios para la construcción de la nueva sociedad civil de la modernidad son los principales reguladores del complejo simbólico cultural.

Una de las consecuencias más sensibles y no menos debatidas que trajo consigo la construcción de la sociedad civil fue la progresiva erosión - por otra parte inevitable - de la concepción religiosa de la vida. La paulativa modernizacion activó un doble movimiento: por un lado, la secularización y prosaización trajo una visión más racionalista del mundo coincidente con el afianzamiento del positivismo; y, por otra, el mismo sentimiento de crisis religiosa incentivó diversas modalidades sacralizadoras como compensación del vacío que iba dejando el escepticismo. Por ello, reivindicar la poesía, la tradición, la moral y ciertas formas de sacralización que adquiere la patria, es la vía de ataque al materialismo reinante. Tal vez esto pueda explicar la extensa difusión que consiguió la literatura didáctica y de tono ejemplarizante que circuló en folletos y libros a partir de la segunda mitad del siglo. Una necesidad casi imperativa de escribir tratados de moral, de condensar valores éticos en forma de pensamientos o de máximas que fuesen de útil guía para el ciudadano cuyos nuevos hábitos citadinos lo alejaban de la lectura de la Biblia. En cierta forma, estos manuales empiezan a ocupar el lugar que antes ejercía el libro sagrado. El manual será ahora la "biblia" de la vida profana; dirá la ley del ciudadano correcto; y de su cumplimiento dependerá el mayor o menor éxito que este ciudadano tenga en el reino material de la civilización. Es interesante observar que durante el largo período del guzmanato, si bien las publicaciones de tema literario (220) ocuparon el primer lugar, el segundo rubro lo cubrieron las publicaciones didácticas (105) y de religión cristiana (86); y los libros de tema histórico, entre ellos 52 homenajes a la figura de Simón Bolívar, alcanzaron el tercer lugar.

El debilitamiento del poder de la iglesia frente al proceso de laización fue reemplazado por una nueva necesidad de afirmación de principios morales, que halló su expresión en esta abundante literatura moralizante que estuvo básicamente dirigida a la configuración de la nueva ética burguesa. El Manual de Carreño, como otros textos por el estilo, fue una de las modalidades discursivas más significativas de los nuevos sectores urbanos en crecimiento que necesitaban, ante una perspectiva más desacralizada de la vida, aparecer en el escenario social como una clase moralmente acreditada. Los nuevos tiempos exigían otros fundamentos éticos. En este sentido, la lectura que se hacía cotidianamente de la 
Biblia en el seno familiar fue reemplazada por estos manuales, que pasaron a convertirse en las biblias de la conducta privada y pública del ciudadano moderno.

Pero este remplazo (del texto sagrado por el profano) no va a significar necesariamente una mayor flexibilización del conjunto de reglas que controla el cuerpo social. Por el contrario: si bien se produce un resquebrajamiento del antiguo régimen señorial $\mathrm{y}$, con ello, una democratización en muchos aspectos de la vida social, ciertas prácticas discursivas -como los manuales - refuerzan, a través de su estructura retórica, el mismo carácter autoritario, impositivo y obligatorio de la tabla de mandamientos. De este modo, el nuevo texto laico reproduce en su tipología discursiva el mismo carácter del texto sagrado, porque reimplementa el sentido de verdad absoluta de sus contenidos, y programa al destinatario para su más apegada obediencia. Curiosamente, el manual se torna en el "libro sagrado" de esta nueva cotidianeidad: quien sigue fielmente las reglas tiene garantizada la entrada al reino de la "civilización", que equivale al ascenso social y al éxito en los negocios.

Los manuales - y el de Carreño es el más paradigmático- cuya variedad asumió formas tan diversas como populares, dieron a estos sectores medios a manera de panacea un recetario ético, no sólo para ubicarse con cierta "elegancia" y "etiqueta" dentro del clima urbano, sino también para lograr su ascenso dentro de una sociedad para la cual el que tenía dinero y sobre todo aprendía "maneras" tenía asegurado el éxito social: "El tacto social ... debe considerarse como el más alto y más sublime grado de la cortesanía ...; y es por esto que las personas de tacto son las que mejor conocen los medios de ocupar siempre en sociedad una posición ventajosa ... En muchos lugares de esta obra se encuentran reglas que tienden evidentemente a formar en nosotros el tacto social" (255, subrayado mío).

Ese "nosotros" del Manual de Carreño representa la materialización de un nuevo sujeto social, que ya para mediados de siglo ha ido cobrando suficiente conciencia de su importancia en el escenario histórico para lograr articular su palabra en el espacio del orden discursivo. En otras palabras, el Manual es la expresión de los nuevos sectores urbanos y de su conciencia acerca del poder que tiene la escritura como estrategia modernizante y civilizatoria.

El hablante del Manual forma con su destinatario una comunidad imaginaria bien delimitada; ese "nosotros" son los "dueños de casa"; los nuevos dueños de casas ubicadas en centros urbanos; casas amplias con varios ambientes, salones, comedores (P.e. después de la comida, se debe pasar a una sala para tomar el postre, y luego a otra para el café), dormitorios, jardines, habitaciones para no pocos "sirvientes". El Manual se dirige al propietario de bienes, al hombre de negocios, a la dueña de casa, a una clase que tiene el suficiente poder adquisitivo para tener varios sirvientes, carruajes, vajillas, porcelanas, alfombras, estar en capacidad de dar fiestas, recibir visitas, ir a teatros, estar a la moda, hacer viajes en barco e ir a grandes hoteles. La servidumbre, el pueblo y los sectores de rancio abolengo señorial forman esa otredad no aludida en el Manual.

Es el texto que expresa el código ético de una nueva clase; configura las estrategias para convertirse en ese nuevo sujeto urbano, moderno, ciudadano burgués. Por eso es un "manual": es la guía que le abre las puertas a cualquier hijo de vecino para ubicarse en la escala social a través de las maneras, de las apariencias. Estos sectores no estaban dotados de aquella tradición patricia que les hubiese podido dar un prestigio incuestionable para 
ejercer su reciente hegemonía. Es una clase que debe educarse en todos los sentidos; necesita adquirir modales, otros hábitos, desde su higiene íntima, cómo comer, hablar, caminar, mover el cuerpo, dirigir la mirada, hasta la relación con los demás en diversas situaciones. Y en la medida en que estas maneras sean más ceremoniosas, complejas, alambicadas y rígidas (recuérdese la variedad de tenedores, cuchillos, cucharas, copas, vasos y servilletas que deben usarse en la mesa de acuerdo con los diferentes platos; el complejísimo código de las presentaciones especiales; la oportunidad de la visitas, de su duración; el modo de conducirnos en la mesa ofrece 53 reglas a seguir) dicen de la jerarquía y poder sociales del ciudadano. Como nueva clase debe ser reconocida y autentificarse dentro de ciertos parámetros de prestigio: es el teatro de la etiqueta, la rigidez en apariencia, la máscara de la contención. El manual, en tanto género discursivo, es el ejercicio del poder escritural del sujeto burgués, del ciudadano acomodado, que debe disciplinar al "bárbaro" que lleva adentro.

Esa comunidad conformada por el "nosotros" del Manual guarda una posición equidistante tanto de los sirvientes como de "otras personas de mayor respetabilidad que nosotros" (228), es decir, de personas que están en una situación de poder. El sujeto enunciativo revela tener una clara conciencia de su poder económico, así como de que su futura ingerencia en "la cosa pública" va a depender de las relaciones que establezca con los grupos hegemónicos (de allí la extensión que el Manual dedica a la conducción en sociedad). Sabe también que de sus maneras y de sus máscaras ("sacrificándonos cada vez que sea necesario"; "dominando nuestro ánimo y nuestro semblante, y mostrándonos siempre afables y joviales") va a depender su reconocimiento social y su posible relación con asuntos administrativos y políticos del Estado moderno. Recordemos que el gobierno de Guzmán Blanco se apoyó fundamentalmente en esta burguesía comercial y financiera, que venía constituyéndose desde hacía dos décadas. Es interesante observar cómo desde los años de 1850 este sector ya tenía en el Manual un vocero de sus aspiraciones. Desde 1870 halla su progresiva afirmación como clase hegemónica conjuntamente con la formación del Estado moderno. La modernización emprendida por el guzmanato puede llevarse a cabo porque encuentra eco en estos sectores ya sensibilizados para el lujo, la sofisticación y el gran teatro de la calle. Carreño diseña el sujeto adecuado para la deseada Caracas de Guzmán Blanco, así también el ciudadano de Buenos Aires, de Santiago, Lima, Bogotá, México ... Es el habitante imaginado por los letrados de la modernización.

El Manual, al mismo tiempo, materializa y configura los valores de la sociedad que debía llevar a cabo la modernización de las ciudades latinoamericanas en el siglo XIX. En este sentido, éste tipo de texto modeliza en el nivel de la construcción de las individualidades, de la percepción del cuerpo y de las relaciones interpersonales, los nuevos valores del liberalismo económico. Estructura para la vida cotidiana los valores burgueses. Con esto no queremos decir que en la Venezuela del siglo XIX haya surgido de hecho ni una burguesía fuerte como tampoco haya habido transformaciones socio-económicas decisivas de esta clase. Sí queremos subrayar que, aunque la formación social en este caso haya sido bastante híbrida (en el sentido de fusionarse el patriciado terrateniente con el sector comercial y financiero), se fue implementando una sensibilidad acorde con los valores éticos de la burguesía en general. 
Ahora la virtud va a estar relacionada con la posesión de dinero y la solvencia de las deudas: "llevemos siempre una cuenta exacta en que aparezcan nuestras deudas, nuestras acreencias y nuestros gastos ... El primer descuido en que incurramos en materia de pagos, será el primer paso que demos hacia la pérdida de nuestro crédito" (42-43). Una sociedad monetarizada acaba con la antigua concepción del ocio. El tiempo vale oro, y se mide la rentabilidad del mismo: "la vida es muy corta, y sus instantes corren sin jamás detenerse; así es que sólo en la economía del tiempo podemos encontrar los medios en que nos alcance para educarnos e ilustrarnos, y para realizar todos los planes que puedan hacerla útil a nosotros mismos y a la sociedad" (43). Hacerlo todo con método pide Carreño, y esto no es otra cosa que la racionalización utilitaria (mercantilista) del hombre y sus relaciones. Como muestra, la duración de las visitas está estrictamente regulada según su carácter: "las visitas de negocios no deben extenderse más allá del tiempo absolutamente indispensable ... Una visita de presentación durará siempre de quince a veinte minutos ... Las visitas de ceremonia duran de diez a quince minutos ... y sólo hasta una hora cuando tienen por objeto cumplidos y demostraciones especiales, como ofrecimientos, felicitaciones, etc." (181).

Los nuevos tiempos - y estamos hablando de los años que anteceden a la Guerra Federal-prescriben el trabajo, el ahorro y el estudio como fuentes de acreditación social: "a nadie le es lícito permanecer en la ociosidad; y sólo le estará permitido permanecer en la cama no más de siete horas ... El que no está dedicado al estudio, debe estarlo al trabajo en alguna industria útil" (51). Los aires de la República, si bien no alteran grosso modo las estructuras patriarcales de una sociedad profundamente anclada en los valores de la tierra, están perforando la concepción señorial de la vida para desplazar los valores hacia el potencial del individuo que se hace a sí mismo. Dependerá de su esfuerzo (trabajo, ahorro, dinero, maneras, corrección y represión) el éxito que logre tanto en su "hacienda" privada como en los asuntos públicos.

En esta también nueva división del trabajo y de los sexos la concepción aparentemente romántica y mixtificada de la mujer como "dulce ángel del hogar" cumple una función decisiva en la consolidación de la riqueza personal: "en la mujer es el método acaso más importante que en el hombre ... so pena de acarrear a su familia una multitud de males de alta trascendencia. Hablamos del gobierno de la casa, de la inmediata dirección de los negocios domésticos, de la diaria inversión del dinero ... La mujer inmetódica ofrecerá ... el desorden a todo el interior de su casa; al desperdicio del tiempo se seguirá el desperdicio del dinero ..., y a los empeños la ruina de la hacienda" (44-45). La reducción burguesa de la mujer al espacio doméstico selló en esos tiempos el sentido profundamente mercantilista que se ocultaba en toda la retórica que edulcoraba esta imagen de la mujer. La distribución de masculino=espacio público y femenino=espacio doméstico son el envés y revés de una misma situación pragmática: la consolidación de una clase ávida de riqueza que se apoya en la familia y el Estado moderno.

Lejos de una democratización de la sociedad, los nuevos tiempos traen una también nueva estratificación social. Se necesitaban los mecanismos de las máscaras democráticas para romper el orden tradicional, y proponer en realidad otros basamentos que fundamentasen jerarquías igualmente rígidas. Los sectores medios proponen valores para abrirse paso y acomodarse; pero al mismo tiempo limitan el ascenso, en principio, a la 
posesión de dinero y maneras. El Manual de Carreño está impregnado por el discurso de la diferencia; su escritura va dibujando fronteras que delimitan los que se van a encontrar afuera y adentro del espacio legitimado por la regla; así también distribuye a los sujetos de acuerdo a ciertas cuotas de poder en superiores e inferiores.

En primer lugar, autentifica como ciudadanos de la nación al habitante de la ciudad (es manual de la urbe); por consiguiente, el habitante del campo está excluído: no tiene posibilidad alguna de adquirir maneras puesto que no es el destinatario del texto. Así mismo, no forman parte de esta comunidad escriturada ni los niños y sirvientes ("a ninguna fiesta, sea de la naturaleza que fuere, y aun cuando se trate de una reunión de confianza, debemos llevar jamás niños ni criados", 196), ni las capas medias bajas, los esclavos como tampoco la oligarquía señorial. Y, en segundo lugar, va ubicando a los sujetos implicados en una escala de gradaciones verticales ("cuando una persona ha de pasar por delante de otra, el inferior cederá siempre el paso al superior, el caballero a la señora, y el que va a caballo al que va a pie", 84-85) de acuerdo a la edad ("no tomamos nunca asiento en la mesa antes que lo hayan hecho nuestros padres, o cualesquiera otras personas de mayor respetabilidad", 228), al parentesco ("no es de buen tono que un caballero baile con su esposa, ni con ninguna otra señora con quien le liguen estrechas relaciones de parentesco", 201), al sexo ("tampoco es lícito a un caballero, y mucho menos si es joven, el detenerse a conversar con una señorita o señora joven ... por muy íntima que sea la amistad que con ella tenga", 87), al estado civil, a la situación económica o naturaleza de profesión ("por regla general jamás debemos detener a los hombres de negocios en horas de trabajo, sino con el objeto de hablarles de asuntos para ellos importantes", 83), al cargo público que ocupen o investidura que tengan ("cuando la persona presentada está investida de un título de naturaleza permanente, como el de Obispo, Doctor, General, etc., el título se menciona antes del nombre; más cuando aquel tan sólo es inherente a la posesión de un empleo de naturaleza transitoria, como el de Representante de la Nación, Ministro de Estado, Tesorero, etc., va generalmente pospuesto", 143).

La modernización rearticula en esencia una estructura conservadora del orden social, profundamente impregnada por el mismo impulso elitista de la antigua sociedad colonial. Puntualiza la analogía entre pares y la diferencia y discriminación entre desiguales: "las atenciones y miramientos que debemos a los demás no pueden usarse de una manera igual con todas las personas indistintamente. La urbanidad estima en las categorías establecidas por la naturaleza, la sociedad y el mismo Dios: así que obliga a dar preferencia a unas personas sobre otras, según su edad, el predicamento de que gozan, el rango que ocupan, la autoridad que ejercen y el carácter de que están investidas ... Según esto, todas las personas entre las cuales existen desigualdades legitimas y racionales, exigen de nosotros actos diversos de civilidad y etiqueta ... basados todos en los dictados de la justicia y de la sana razón" (12, subrayado mío). La naturaleza de esta "razón"-que fundamenta el discurso de los manuales - es la misma que subyace en todo el positivismo filosófico, que legitimó en la práctica la modalidad conservadora y autoritaria del Estado latinoamericano inclusive hasta entrado el siglo XX.

El texto va fijando los mecanismos de pertinencia del "nosotros", aquellos que pertenecen al territorio de esta nueva ley que debe ser enunciada. Paradojalmente, el que maneja el código de las diferencias puede entrar en el espacio del reconocimiento social. 
En realidad, el Manual pone en contacto al individuo con los otros. Pero con un "otro" que es él mismo, con sus otros posiblemente iguales; sus con-ciudadanos. El otro "otro" está presente a lo largo del texto. La misma escritura va progresivamente delimitando los que se quedan afuera: los criados ("por sus defectos o deformidades naturales"), el menesteroso, el desaseado, el deprimido, el que cede a los arranques de ira, el que llora y ríe en público, el que habla de sus flaquezas y de las ajenas. El régimen de las exclusiones va más lejos: el "otro" dentro del mismo yo también es segregado, debe ser reprimido y controlado. La escritura del Manual no sólo habilita la diferencia, sino también impone el discurso de la prohibición. Van aparejadas a la letra la vigilancia y el castigo. Y es en este punto donde se estrechan los lazos entre el ejercicio de una escritura que informa, inviste, circunscribe al tiempo de constituirse en mecanismo de censura y represión.

Siguiendo este orden de cosas, la modernización viene aparejada con un progresivo encorsetamiento del hombre; con un considerable aumento de discursos restrictivos y penalizantes. Casi se podría decir que a mayor modernización del sujeto social, es decir, cuanto más acabada sea su calidad ciudadana, tanto más amplia y profunda es su absorción de discursos y prácticas represoras. La relación entre modernización y disciplinamiento del sujeto y del imaginario es una relación tensa y altamente contradictoria que no se puede comprender unidireccionalmente. No es menos cierto que también la modernidad trajo elementos liberadores y más democráticos. La dinámica de todos estos factores es compleja. Por un lado, se produce un consumo masivo de estos manuales: gran parte de los axiomas de la sociedad finisecular siguen siendo patriarcales, y ante los cuales la etiqueta propuesta por los manuales reacomodaba y actualizaba el ritual social a los nuevos tiempos más sensibles al manejo de las buenas maneras y apariencias que a la posesión de prestigiosos apellidos señoriales. Pero, por otro lado, aún cuando la censura y los códigos de prohibición mantenían su vigencia, no podemos olvidar la abundante literatura del Modernismo llena de aires transgresores, donde la liberación del eros y de ese imaginario reprimido cobra formas ambiguas y oscilantes aún no deslastradas del pecado y de la culpa. ${ }^{1}$ Obviamente cada género extiende su circuito de poder que entra en fricción con el dominio y régimen de otras prácticas discursivas. El poder de la ficción controla su campo, y los manuales el suyo.

El paisaje semántico del Manual va construyendo el perfil del sujeto deseado a partir de su propia negación. El conjunto de reglas avanza siguiendo el régimen de la prohibición ("no olvidemos jamás", "no permitamos nunca", "no mantengamos ni un instante", "tampoco están exceptuados", "evitemos en cuanto sea posible", "no permitamos nunca", "ni esta ni ninguna otra operación está permitida"), o por descalificación ("es vulgar", "grosero y desagradable", "intolerable", "son actos asquerosos y altamente inciviles", "excita

\footnotetext{
${ }^{1}$ Sin duda, podría ser interesante estudiar la interacción que hubo entre estos textos que postulan la regla, el orden, el método, la contención la negación del cuerpo y de la fantasía, textos autoritarios y penalizantes, y el espacio que abría la novela, género que para muchos conservadores era considerado altamente peligroso por su capacidad para incitar las "bajas pasiones" y conductas desviadas. ¿Qué espacio abre la novela parsa satisfacer el deseo dentro del imaginario, el despliegue de las subjetividades del yo, el mundo del eros del buen ciudadano o de la buena ciudadana? Doris Sommer nos ha dado una respuesta política del idilio, que no deja de ser una lectura atractiva y que posibilita otras interpretaciones dentro de esta línea.
} 
un asco invencible", "cosas repugnantes", "mala impresión", "fuertes sensaciones de asco"), o por imposición absoluta ("es una regla someternos estrictamente", "procuremos aprender","debemos abstenernos", "siempre debemos", "guardémonos de", "estamos obligados a"). El sujeto enunciativo del Manual se decide como instancia administradora de poder: es una voz que asume la autoridad de una clase en formación, y como tal sabe que para serializar los individuos de su grupo debe ser autoritaria; demarcar claramente los límites con una proyección punitiva; ofrecer el espacio del deber ser y de lo prohibido. Así, el seguimiento fiel de la letra puede llevar al disciplinamiento de la sensibilidad bárbara a una más civilizada. El costo de esta reeducación del sujeto va a significar la negación de su cuerpo, la represión de su deseo, la violación de su naturaleza espontánea y la cancelación de la intimidad de su espacio privado.

El Manual dibuja el espacio de la barbarie en el terreno de las subjetividades y de los cuerpos. Así como el Facundo de Sarmiento crea para el imaginario los horizontes de la barbarie geográfica y social que la escritura domestica, el texto de Carreño diseña en una doble dirección el carácter natural del cuerpo y de los impulsos espontáneos del espíritu como territorios indeseados de la barbarie personal, y los moldes corporales y conductuales de la anhelada civilización. Las funciones naturales del cuerpo, las necesidades orgánicas, los humores, sudoraciones, olores, según el Manual, pasan a engrosar la lista de lo que la censura social reconoce como zonas abyectas y oscuras. Todas las manifestaciones corporales (del cuerpo consciente e inconsciente) pertenecen ahora al territorio de la barbarie. Y su enumeración podría no ser corta: estornudar, bostezar, sonarse la nariz, estirarse, reirse, roncar, aplaudir, escupir, gesticular, hacer ruido, secarse el sudor, comer dulces, frutas o en exceso, tocarse partes del cuerpo o tocar a otro, moverse durante el sueño o adoptar ciertas posturas, mirar a otros, mover las manos, beber, preguntar, fumar, discutir, responder ... deben ser encorsetados en aras de un individuo más "civilizado" a fuerza de múltiples repliegues.

Presumimos que el sentido que aquí adquiere el "ser civil", urbano y moderno, está en relación con la progresiva negación del cuerpo ("la costumbre de levantarnos en la noche a satisfacer necesidades corporales, es altamente reprobable", 48; "no acostumbremos llevar la mano a la cabeza, ni introducirla por debajo de la ropa con ningún objeto, y menos con el de rascarnos", 23); negación de una cultura que estimulaba la sensualidad entre los sentidos y las cosas ("son actos extraordinariamente impropios y groseros el aplicar el olfato a las comidas y bebidas", 235); la generosa espontaneidad y el sentido de solidaridad con otros ("jamás brindemos a nadie comida ni bebida alguna que hayan tocado nuestros labios; ni platos u otros objetos de esta especie que hayamos usado", 35; "no ofrezcamos a nadie nuestro sombrero, ni ninguna otra pieza de nuestros vestidos que hayamos usado", 35); la libertad del campo visual, el placer del voyeurismo ("no es propio de personas bien educadas dirigir desde su casa miradas escudriñadoras a las casas inmediatas", 73; "no fijemos detenidamente la vista en las personas que encontremos, ni en las que se hallen en sus ventanas, ni volvamos la cara para mirar a las que ya han pasado", 82); la espontánea expresión de los deseos ("son actos vulgares e inciviles ... tocar los vestidos o el cuerpo de aquellos a quienes se dirige la palabra. La mujer que tocase a un hombre no sólo cometería una falta de civilidad, sino que aparecería inmodesta y desenvuelta", 120; "no debe olvidarse nunca que en las fiestas no se va únicamente a satisfacer los propios gustos y caprichos", 
201); la manifestación de los estados anímicos ("si al levantarse tiene su ánimo afectado por algún disgusto, lo oculta cuidadosamente desde el momento en que alguno le dirige la palabra", 52; "tengamos especial cuidado de no perder jamás en sociedad la tranquilidad de ánimo", 108; "cuando nos encontremos afectados por algún accidente desagradable, dominemos nuestro ánimo y nuestro semblante, y mostrémonos siempre afables y joviales", 187); el repliegue del YO y del ámbito familiar ("es una vulgaridad hablar en sociedad de nuestra familia, de nuestra persona, de nuestras enfermedades, de nuestros conflictos, de nuestros negocios", 113); la restricción de la palabra y la prohibición a la réplica ("en ningún caso entremos en discusión con una persona", 108; "la más grave de todas las faltas que pueden cometerse en sociedad, es la de desmentir a una persona", 139; "no está admitido contradecir en ningún caso a las personas que se encuentran en un círculo de etiqueta", 139).

De algún modo estimamos que lo que a partir del Manual se etiqueta como "incivil" y "repugnante" tiene que ver con una concepción de la cultura del cuerpo y de la subjetividad anterior a 1860 más flexible, familiar y menos aherrojada. Quizás a excepción de las élites mantuanas, el resto de la población participaba de códigos éticos mucho menos rígidos. La sensibilidad popular estaba lejos de estas inhibiciones. Pero en la medida en que el nuevo sujeto burgués vió sus posibilidades materiales de ascenso, quiso adoptar las maneras exteriores de las clases patricias, clases que tenían como natural los hábitos de corte asimilados por tradición. De este modo, la conducción espontánea, expresiva, sensual, contestataria, generosa, gratuita, cálida, voluptuosa, dadora de estos sectores es sacrificada en aras de la construcción de un individuo modélico para funcionar como ciudadano ideal $\mathrm{y}$ obediente en un Estado autoritario y hegemónico como lo fue particularmente el guzmanato (1870-1888) y posteriormente el gomecismo (1909-1935). Ubicarse en el espacio del reconocimiento público implicaba una considerable cuota de sacrificio, de amordazamiento, de sublimación del deseo y de enmascaramientos. La negación y cobertura del cuerpo individual ("no está permitido a un hombre el permanecer en su casa sin corbata, en mangas de camisa, sin medias, ni con los pies mal calzados", 55; "no está admitido el nombrar en sociedad los diferentes miembros o lugares del cuerpo", 124) podría tomarse como un ejemplo simbólico para significar el potencial contestatario e impulso democrático del cuerpo social de estos sectores medios que debían ser refrenados y contenidos. En este sentido, el ciudadano "civilizado" o "buen ciudadano" es aquel que calla, que no discute, que no ve al otro, no come ni bebe, desconoce su cuerpo y el cuerpo del otro, aprisiona su yo, escuda sus afectos. El Estado en su proyecto de la formación nacional necesita de estos ciudadanos, dóciles, reprimidos, prisioneros bajo las máscaras de la urbanidad de las buenas maneras.

La relación de contigüidad entre civilización/progreso/modernización y sacrificio/ apariencia/dominación se hace evidente: "suframos con afectuosa resignación y prudencia, las pequeñas contradicciones que hemos de encontrar a cada paso en el seno de la vida doméstica, y ahoguemos al nacer todo germen de discordia que pueda venir a turbar la armonía y la paz que son el fundamento del orden, el contento y el bienestar" (64). El disciplinamiento de las inclinaciones vitales hacia la adopción de una naturaleza artificial y codificada descansa en el artificio de la letra. La construcción del ciudadano imaginado se da a través de la operación escritura/lectura que va modelando individualmente cada 
usuario del Manual. Así, la escritura aplana y unifica la diversidad, y establece esas comunidades imaginadas. Efectivamente, el sujeto en su proceso civilizatorio sufre varios grados de cosificación: el primero, en relación con la misma escritura: para ser civilizado debe no sólo leer, sino seguir la regla; el segundo, lo induce a adoptar formas otras que deben ser superpuestas a las naturales; el tercero, le lleva a vivir en un mundo donde el contínuum, lo espontáneo, orgánico y heterogéneo del flujo vital es alterado por un régimen de unidades discretas. Y es en este último sentido que el género de los manuales, en tanto prácticas discursivas, potencializa el concepto de enajenación de las sociedades modernas. En su estrategia enumerativa debe nombrar las partes y secuencias de todo; por lo tanto, fragmenta y secciona, distribuye y encasilla para (re)construir un nuevo orden a base de las partes de un cuerpo desmembrado y encubierto, de un cuerpo social estratificado en nuevas diferencias. Pero además, cada fragmento e intersticio del espacio privado y público al estar codificado está siendo vigilado por el poder de la palabra.

El diseño escriturario de la comunidad nacional tiene a su cargo ofrecer una representación imaginaria del sujeto y de sus espacios, ya sea creándole la geografia de la barbarie, o bien distribuyéndole su territorialidad más cercana en espacios privados y públicos. Sin embargo, tanto lo público como lo privado está permeado por la misma autoridad reguladora y voz disciplinante. El conjunto de reglas del Manual penetra en el "sagrado" recinto familiar para formar desde el hogar a los individuos que serán los ciudadanos al salir a la calle. El espacio doméstico es el primer escenario donde el sujeto aprende su propio encorsetamiento: "y como nuestros hábitos en sociedad no serán otros que los que contraigamos en el seno de la vida doméstica, que es el teatro de todos nuestros ensayos, imposible será que consigamos llegar a ser metódicos y exactos, si no cuidamos de poner orden a todas nuestras operaciones en nuestra propia casa" (40, subrayado mío).

Experimentar el orden era suprimir la espontaneidad y aprehender las apariencias ("usemos de un discreto disimulo", "aparezcamos como si nada hubiésemos advertido", "dominémonos hasta el punto de que ni en nuestro semblante se note que nos hemos enojado", "sujetándonos en todo a las reglas"). La concepción de la personalidad inmanente llevó a cuidar con esmero cada detalle, porque la personalidad era la forma exterior, y de su rigidez e impasibilidad dependía la minimización de los impulsos contradictorios. Un hogar estable era aquel que había logrado introducir el orden y el método, es decir, la rutina represiva de las reglas. Con lo cual se creía que sus miembros crecían de manera saludable porque habían dominado sus pasiones y acostumbrado sus cuerpos a la asepcia de una higiene diaria. Por consiguiente, cuando se habla del "espacio privado" como ámbito de liberación de las reglas y como espacio opuesto al público (donde éstas imperan) es un simple efecto producido por la misma represión del deseo que utopiza lo privado y familiar como ese territorio libre de normas y leyes. Por un lado, la privatización de la experiencia familiar en el siglo XIX parece trasladar a la familia fuera de las agitaciones del mundo externo; pero, por otro, la idea de la personalidad inmanente vuelve a arrojar sobre el espacio privado las mismas ansiedades de orden y represión que regían la vida pública. Tanto el deseo de retirada como la construcción de la sociedad externa son elementos sociales, por cuanto que público y privado son dos instancias igualmente públicas que debían ser controladas. 
A estas alturas, la lectura y la confianza en esta escritura legal que constituye al sujeto (de la misma manera que las constituciones) en su acontecer cotidiano público y privado, es el reverso complementario del aparato estatal igualmente autoritario que se erigió en las últimas décadas del siglo como parte del proceso modernizador. El Manual sirve a este nuevo Estado en la medida en que forma ciudadanos efectivamente "civilizados", acordes para ser los actores de las no menos modernas ciudades en proyecto; pero sobre todo útiles porque han debido "adquirir el hábito de dominar las pasiones", "guardarse de proferir cualquier expresión", "moderar la medida de los afectos del ánimo", es decir, domesticados desde el hogar para rendir la necesaria obediencia al poder del Estado. El aparato estatal guzmancista desarrolló una retórica del poder basada en la teatralidad e hipertrofia de los símbolos patrios como modo de legitimar el carácter absoluto y omnímodo del Estado en la persona de Guzmán Blanco. Se requería de ciudadanos graves y serios, estirados y empaquetados para que, siguiendo el guión que les prescribía el Manual, pudiesen transitar, cual actores de un inmenso teatro urbano, las avenidas y plazas recientemente construidas como señal del progreso y modernización que estaba alcanzando el país.

Género menos, no precisamente literario, el Manual es el gran competidor complementario de las novelas por entrega, del melodrama, que empieza a circular profusamente a partir de la década de 1860 . Irrumpe en las incontroladas intimidades domésticas; invade la espontánea cotidianeidad del hogar y empieza a moldear al deseado ciudadano desde la casa familiar para convertirlo en un sujeto tan rentable y productivo como reprimido: es el nuevo hombre de negocios en el plano de los asuntos públicos, y la dueña de casa en el plano de los asuntos domésticos. Nada más ingenuo pensar que el nuevo Estado sólo controlaría el espacio público.

$\mathrm{El}$ anhelado proyecto de construir sociedades civilizadas bajo el lema del "orden y del progreso" no sólo debía atender el control de la cosa pública, sino también el control y la redireccionalidad del espacio privado. Así, la escritura autoritaria del Manual-que por otra parte bien puede darse la mano con el poder del Estado en su versión "familiar"contribuye conjuntamente con otras prácticas discursivas a moldear el sujeto social que debía habitar esas utópicas naciones. Si el Facundo de Sarmiento fue uno de los textos fundacionales decisivos que orientaron la construcción cultural del imaginario de las sociedades latinoamericanas, el Manual no lo fue menos. Ambos articularon de modo diverso el axioma central de la modernización: la civilización de la barbarie.

\section{BiBLIOGRAFÍA}

Anderson, Benedict. Imagined Communities: Reflections on the Origin and Spread of Nationalism. Londres: Verso, 1983.

Amorós, Celia. Hacia una crítica de la razón patriarcal. Barcelona: Editorial Anthropos, 1985.

Aranguren, José Luis. Moral y sociedad. La moral española en el siglo XIX. Madrid: Ediciones Taurus, 1981.

Armstrong, Nancy. Desire and Domestic Fiction. Nueva York: Oxford University Press, 1987.

The Imaginery Puritan: Literature, Intellectuals, and the Origins of Personal Life. Tennenhouse: California University Press, 1992. 
Bajtin, Mijail. La cultura popular en la Edad Media y en Renacimiento. Barcelona: Barral Editores, 1974.

Barrán, José Pedro. Historia de la sensibilidad en el Uruguay. Tomo I: La cultura "bárbara" (1800-1860), Tomo II: El disciplinamiento (1860-1920). Montevideo: Ediciones de la Banda Oriental, 1989 y 1990.

Béjar, Helena. El ámbito intimo. Privacidad, individualismo y modernidad. Madrid: Alianza, 1988.

Berman, Marshall. Todo lo sólido se desvanece en el aire. México: Siglo XXI Editores, 1988.

Bhabha, Homi. Nation and Narration. London-New York: Routledge, 1990.

Búfalo, Enzo del. La genealogía de la subjetividad. Caracas: Monte Ávila Editores, 1991.

Burns E., Bradford. The Poverty of Progress. Latin American in the Nineteenth Century. Berkeley: University of California Press, 1982.

Castellanos, Rafael Ramón. Caracas 1883. 2 tomos. Caracas: Academia Nacional de la Historia, 1983.

Carreño, Manuel Antonio. Manual de Urbanidad y Buenas Maneras. 1854; París: Casa Editorial Garnier Hermanos, 1927.

Certeau, Michel de. Heterologies. Discourse on the Other. Minneapolis: University of Minnesota Press, 1985. Practice of Everyday Life. 1984.

Congreso de la Republica (editores). Venezuela 1883. 3 volúmenes. Caracas: Ediciones del Congreso de la República, 1983.

Díaz Sánchez, Ramón. Guzmán. Elipse de una ambición de poder. 2 volúmenes. 1952; Madrid-Caracas: Edime, 1969.

Engels, Federico. El origen de la familia, la propiedad privada y el Estado. 1884; Bogotá: Ediciones Géneses, 1990.

Firth, Raymond. Symbols: Public and Private. Nueva York: Ithaca University Press, 1973.

Foucault, Michel. El orden del discurso. Barcelona: Tusquets, 1973. Historia de la sexualidad. México: Siglo XXI Editores, 1977, 1985.

_L L L verdad y las formas jurídicas. Barcelona: Gedisa, 1980, 1991. Las palabras y las cosas. México: Siglo XXI Editores, 1979. Microfisica del poder. Madrid: Ediciones La Piquete, 1978. Vigilar y castigar. Nacimiento de la prisión. México: Siglo XXI Editores, 1976, 1988.

Goody, Jack. The Logic of Writing and the Organization of Society. Literacy, Family, Culture and the State. Cambridge: Cambridge University Press, 1986.

Gutiérrez Girardot, Rafael. Modernismo. Barcelona: Montesinos, 1983.

Hobsbawm, E. J. Nations and Nationalism since 1780. Cambridge: Cambridge University Press, 1991. and Terence Ranger (editores). The Invention of Tradition. Cambridge: University Press, 1983. 
Hunt, Lynn. The Family Romance of the French Revolution. Berkeley: University of California Press, 1992.

The New Cultural History. Berkeley: University of California Press, 1989.

Kirkpatrick, Susan. Las románticas. Escritoras y subjetividad en España. 1835-1850. Madrid: Ediciones Cátedra, 1989.

Lacan, Jacques. La familia. Barcelona: Editorial Argonauta, 1978.

Laporte, Dominique. Historia de la mierda. Valencia: Pre-textos, 1980.

Legendre, Pierre. El amor del censor. Ensayo sobre el orden dogmático. Barcelona: Editorial Anagrama, 1979.

Litvak, Lily. Erotismo fin de siglo. Barcelona: Antoni Bosch Editor, 1979.

Marcuse, Herbert. Eros y civilización. Barcelona: Ariel, 1984.

Mosse, George L. Nationalism and Sexuality. Madison: The University of Wisconsin Press, 1985.

Naranjo de Castillo, Cira y Carmen G. Sotillo: Producción bibliográfica y política editorial en la época de Guzmán Blanco. Caracas: Academia Nacional de la Historia, 1987.

Nazoa, Aquiles. Caracas fisica y espiritual. 1967; Caracas: Editorial Panapo, 1987.

Rama, Ángel. La ciudad letrada. Montevideo: Fundación Ángel Rama, 1984.

Las máscaras democráticas del modernismo. Montevideo: Arca, 1985.

Ramos, Julio. Desencuentros de la modernidad en América Latina. México: Fondo de Cultura Económica, 1989.

Romero, José Luis. Latinoamérica: las ciudades y las ideas. 1976; México: Siglo XXI, 1984.

Samuels, Shirley (editora). The Culture of Sentiment. Nueva York: Oxford University Press, 1992.

Sennet, Richard. Narcisismo y cultura moderna. Barcelona: Editorial Kairós, 1980.

Silva, Paulette. Una vasta morada de enmascarados. Caracas: Ediciones Casa de Bello, 1993.

Sommers, Doris. Foundational Fictions. The National Romances of Latin America. Berkeley: University of California Press, 1991.

Torres, María Inés de. Ideología estatal, ideología patriarcal y mitos fundacionales: la construcción de la imagen de la mujer en el sistema lírico del Uruguay del siglo XIX. Investigación mimeografiada de CLACSO, 1990.

Thiebaut, Carlos. Historia del nombrar. Dos episodios de la subjetividad moderna. Madrid: Visor, 1990.

Williams, Raymond. The Country and the City. Nueva York: Oxford University Press, 1973.

Zavala, Iris. "Infracciones y transgresiones sexuales en el romanticismo hispánico". Cuadernos Interdisciplinarios de Estudios Literarios, I/1, 1989. 